\title{
Detection of ochratoxin A in tropical wine and grape juice from Brazil
}

\author{
Michelle F Terra, ${ }^{a}$ Guilherme Prado, ${ }^{b}$ Giuliano E Pereira, ${ }^{c}$ Hugo J Ematnéa \\ and Luís R Batista ${ }^{d *}$
}

\begin{abstract}
BACKGROUND: Ochratoxin A (ОTA) is the main mycotoxin found in grapes, wines and grape juices and is considered one of the most harmful contaminants to human health. In this study, samples of tropical wines and grape juices from different grape varieties grown in Brazil were analysed for their OTA content by high-performance liquid chromatography.

RESULTS: The detection and quantification limits for OTA were 0.01 and $0.03 \mu \mathrm{g} \mathrm{L}^{-1}$ respectively. OTA was detected in 13 (38.24\%) of the samples analysed, with concentrations ranging from $<0.03$ to $0.62 \mu \mathrm{g} \mathrm{L}^{-1}$. OTA was not detected in any of the grape juice samples. Most of the red wine samples proved to be contaminated with OTA (75\%), while only one white wine sample was contaminated. However, the OTA levels detected in all samples were well below the maximum tolerable limit ( $2 \mu \mathrm{g}$ $\mathrm{L}^{-1}$ ) in wine and grape juice established by the European Community and Brazilian legislature.
\end{abstract}

CONCLUSION: The results of this study indicate a low risk of exposure to OTA by consumption of tropical wines and grape juices from Brazil.

(C) 2012 Society of Chemical Industry

Keywords: high-performance liquid chromatography; ochratoxin A; wine; grape juice; carcinogen; mycotoxin

\section{INTRODUCTION}

Ochratoxin A (OTA) is a secondary toxic metabolite produced by some species of filamentous fungi of the genera Aspergillus and Penicillium and is often found in a variety of foods and beverages, including wine and grape juice. ${ }^{1}$ OTA has exhibited carcinogenic, nephrotoxic, teratogenic and immunotoxic effects in animals, ${ }^{2}$ leading to its classification as a possible human renal carcinogen (group 2B). ${ }^{3}$ The presence of OTA in grape juice and wine was first reported by Zimmerli and Dick in $1995 .{ }^{4}$ Currently, it is considered to be the principal mycotoxin found in grape derivatives. ${ }^{5}$

Since OTA has been reported in various studies as a grape, wine and grape juice contaminant, international regulatory bodies have undertaken risk assessments to determine the effect of the consumption of this mycotoxin on human health. In 2002 a study investigating OTA ingestion in European Union (EU) countries concluded that, after cereals, wine is the principal source of OTA for humans. ${ }^{6}$

Studies show that fungi of the genus Aspergillus section Nigri, in particular Aspergillus carbonarius, are the main culprits in OTA production in grapes. ${ }^{7}$ In addition, OTA levels vary depending on the type and region of wine as well as the period of harvest. ${ }^{2}$ In fact, studies performed on Brazilian, Argentinian and Chilean grape juices and wines showed that these products contain lower OTA levels than those from Europe. ${ }^{8}$ In addition, red wine has higher levels of OTA than white and rosé wine. ${ }^{9}$ Similar to what has been observed for wine, red grape juice exhibits higher OTA levels than white grape juice. ${ }^{10}$

OTA contamination in grape juice is of great concern, since children are its main consumers and the consumption of juice is greater than that of wine. ${ }^{11}$ Currently, EU legislation permits a maximum of $2 \mu \mathrm{g} \mathrm{L}^{-1}$ OTA in wine and grape juice. ${ }^{12}$ In February 2011, Brazilian legislation also established $2 \mu \mathrm{g} \mathrm{L}^{-1}$ as the maximum tolerable limit for OTA in wine, grape juice and grape derivatives. $^{13}$

To date, only a few studies have investigated the presence and levels of OTA in Brazilian grape-derived products; however, more information is necessary to better determine the possible health risks of the consumption of wines and juices produced in this country. Thus, in the present study, we aimed to evaluate the presence and levels of OTA in wines and grape juices from northeastern Brazil using immunoaffinity and high-performance liquid chromatography (HPLC) analysis.

* Correspondence to: Luís R Batista, Departamento de Ciência dos Alimentos, Universidade Federal de Lavras, Caixa Postal 3037, CEP 37200-000, Lavras, Minas Gerais, Brazil.E-mail: luisrb@dca.ufla.br

a Departamento de Biologia, Universidade Federal de Lavras, Caixa Postal 3037, CEP 37200-000, Lavras, Minas Gerais, Brazil

b Fundação Ezequiel Dias (FUNED), Laboratório de Micotoxinas, Rua Conde Pereira Carneiro, 80, Gameleira, CEP 30510-010, Belo Horizonte, Minas Gerais, Brazil

c Embrapa Uva e Vinho/Semiárido, Rodovia BR 428, Km 152, CEP 56302-970, Petrolina, Pernambuco, Brazil

d Departamento de Ciência dos Alimentos, Universidade Federal de Lavras, Caixa Postal 3037, CEP 37200-000, Lavras, Minas Gerais, Brazil 
Table 1. Grape varieties used to prepare wine samples in study

Wine (grape) sample

Period of preparation (month/year)

Red wines

Syrah Clone 525 RS: IAC-313

$11 / 2009$

Syrah Clone 525 RS: 1103-P

$11 / 2009$

Tempranillo RS: IAC-313

$11 / 2009$

Alicante RS: 1103-P

$11 / 2009$

Syrah without maceration

$12 / 2009$

$11 / 2009$

$11 / 2009$

$11 / 2009$

$06 / 2009$

$06 / 2009$

$11 / 2009$

$06 / 2009$

$09 / 2009$

$09 / 2009$

$12 / 2009$

$12 / 2009$

Carmenère

White wines

Verdejo

$07 / 2009$

Viognier 1

$06 / 2009$

$11 / 2009$

$07 / 2009$

$11 / 2009$

$06 / 2009$

Chenin Blanc 2

Sauvignon Blanc 1

Sauvignon Blanc 2

$11 / 2009$

\section{MATERIALS AND METHODS}

\section{Study region and sample preparation}

Grapes for wine and grape juice samples were obtained from the tropical winemaking region of Brazil $\left(9^{\circ} \mathrm{S}, 40^{\circ} \mathrm{W}\right)$. A total of 23 types of wine sample ( 16 red and seven white) were experimentally prepared from red and white grapes using different treatments, such as clones of grape varieties and rootstocks (RSs) (Table 1). The wines, prepared from the varieties Tempranillo, Petit Verdot, Viognier, Chenin Blanc and Sauvignon Blanc, were obtained in two different winemaking periods in 2009 (Table 1). IAC-313 was classified as a high-vigour RS.

Wine was made from the grape varieties listed in Table 1 using the traditional method $^{14}$ in $200 \mathrm{~L}$ stainless steel vats. Alcoholic and malolactic fermentations were performed at 25 and $18{ }^{\circ} \mathrm{C}$ respectively. The wines were then stabilised and bottled.

The grape juice samples were prepared from three grape cultivars grafted onto different RSs, namely Isabel Precoce, Isabel Precoce IAC-313, Isabel Precoce Paulsen 1103, Isabel Precoce IAC-776, Isabel Precoce IAC-572, Isabel Precoce 313 R2, Rúbea Paulsen 1103, Rúbea IAC-766, BRS Cora IAC-572, BRS Cora IAC-776 and BRS Cora IAC-313, for a total of 11 samples. Grape juices samples were prepared in $20 \mathrm{~L}$ craft juicers via extraction at $75^{\circ} \mathrm{C}$ with flash pasteurisation and subsequent bottling.

\section{OTA analysis in wine and grape juice}

OTA levels in the wine and grape juice samples were measured using HPLC with fluorescence detection as described previously. ${ }^{15}$
Solutions and reagents

The dilution solution contained $10 \mathrm{~g} \mathrm{I}^{-1}$ PEG 8000 and $50 \mathrm{~g} \mathrm{I}^{-1}$ $\mathrm{NaHCO}_{3}$ in purified water. The washing solution contained $25 \mathrm{~g} \mathrm{I}^{-1}$ $\mathrm{NaCl}$ and $5 \mathrm{~g} \mathrm{I}^{-1} \mathrm{NaHCO}_{3}$ in purified water. A stock solution of OTA (Sigma-Aldrich, St Louis, MO, USA) was prepared in toluene/acetic acid $(99: 1 \mathrm{v} / \mathrm{v})$ and stored at $-15^{\circ} \mathrm{C}$. Concentration was determined using a UV spectrophotometer at $333 \mathrm{~nm}$ in accordance with the AOAC method. ${ }^{16}$ A working solution was prepared by appropriate dilution in toluene/acetic acid (99:1 $\mathrm{v} / \mathrm{v})$ for the recovery tests and calibration curve. For the mobile phase, acetonitrile/methanol/aqueous acetic acid (35:35:30 v/v/v) was used, followed by vacuum filtration using a $0.45 \mu \mathrm{m}$ polytetrafluoroethylene (PTFE) regenerated cellulose membrane. Aqueous acetic acid was prepared with a glacial acetic acid solution in purified water $(1: 29 \mathrm{v} / \mathrm{v})$.

\section{Preparation and purification of samples}

The samples were initially cooled to $4{ }^{\circ} \mathrm{C}$, then $40 \mathrm{~mL}$ of each sample was added to $40 \mathrm{~mL}$ of dilution solution and homogenised by agitation for $30 \mathrm{~min}$. This solution was vacuum filtered $(2 \mathrm{~mL}$ $\mathrm{min}^{-1}$ ) using a glass microfibre filter membrane, and $40 \mathrm{~mL}$ of the filtrate was passed through an immunoaffinity column (Ochraprep, R-Biopharm Rhone Ltd, Glasgow, UK) using a Visiprep ${ }^{\mathrm{TM}}$ SPE Vacuum Manifold (Sigma-Aldrich, St Louis, MO, USA) system. The column was washed with $10 \mathrm{~mL}$ of washing solution followed by $10 \mathrm{~mL}$ of purified water. Methanol ( $2 \mathrm{~mL}$, three times) was then added to elute OTA from the column. The eluate was evaporated at $50{ }^{\circ} \mathrm{C}$ under nitrogen vapour. The dry extract was then reconstituted in $250 \mu \mathrm{L}$ of mobile phase. A $50 \mu \mathrm{L}$ aliquot of each standard and sample was used for the subsequent HPLC analysis.

\section{HPLC}

Measurement of OTA levels was conducted using a Shimadzu (Kyoto, Japan) liquid chromatography system with a fluorescence detector (LC-10AD) at wavelengths of 333 and $476 \mathrm{~nm}$ for excitation and emission respectively. A Shim-pack CLC-ODS RP18 column $(5 \mu \mathrm{m}, 4.6 \mathrm{~mm} \times 250 \mathrm{~mm})$ with a Shim-pack G-ODS precolumn $(5 \mu \mathrm{m}, 4 \mathrm{~mm} \times 10 \mathrm{~mm})$ was used at a flow rate of $0.8 \mathrm{~mL}$ $\min ^{-1}$. Samples and standards $(200 \mu \mathrm{L})$ were evaporated under nitrogen and the residues were resuspended in $300 \mu \mathrm{L}$ of boron trifluoride in $140 \mathrm{~mL} \mathrm{~L}^{-1}$ methanol. Samples were then heated at $80^{\circ} \mathrm{C}$ for $10 \mathrm{~min}$ and allowed to cool to ambient temperature before evaporation and resuspension in $1 \mathrm{~mL}$ of mobile phase for injection into the chromatography system. The presence of OTA was determined by the disappearance of the OTA peak and the appearance of a new peak (OTA methyl ester) at longer retention time. OTA levels were calculated from the area of the OTA peaks in samples and standards. Under these conditions the retention time was around $11 \mathrm{~min}$.

\section{Standard addition experiments}

The method for determining OTA in wine and grape juice samples was validated by adding OTA to samples known to be negative for OTA $\left(<0.03 \mu \mathrm{g} \mathrm{L}^{-1}\right)$. OTA was added to $220 \mathrm{~mL}$ of wine at levels of 0.22 and $0.44 \mu \mathrm{g} \mathrm{L}^{-1}$. The sample was blended and allowed to equilibrate for $1 \mathrm{~h}$ at $4{ }^{\circ} \mathrm{C}$. Then five aliquots of $40 \mathrm{~mL}$ each were taken and analysed. OTA was added to $100 \mathrm{~mL}$ of grape juice at a concentration of $2.78 \mu \mathrm{g} \mathrm{L}^{-1}$. The sample was blended and cooled to $4{ }^{\circ} \mathrm{C}$, after which two aliquots of $40 \mathrm{~mL}$ each were taken and analysed. 


\section{Calibration curve}

Standard solutions for HPLC calibration were prepared as follows. The working solution $\left(29.613 \mu \mathrm{g} \mathrm{ml}^{-1}\right.$ in toluene/acetic acid) was obtained by evaporating $800 \mu \mathrm{L}$ of stock solution $\left(111.05 \mu \mathrm{g} \mathrm{ml}^{-1}\right.$ in toluene/acetic acid) in a nitrogen stream followed by resuspension in $3 \mathrm{~mL}$ of mobile phase. Seven-point graphs were obtained with $0.6,5,10,20,30,60$ and $111 \mu \mathrm{g}$ $\mathrm{L}^{-1}$ standards. Calibration graphs were obtained using linear regression of the least squares method and the peak response of each standard injection plotted against OTA concentration. The correlation coefficient was greater than 0.999 . The detection limit (DL) was $0.01 \mu \mathrm{g} \mathrm{L}^{-1}$, calculated as three times the standard deviation of the blank samples divided by the slope of the calibration graph. The quantification limit (QL) was $0.03 \mu \mathrm{g} \mathrm{L}^{-1}$, calculated as ten times the standard deviation of the blank samples divided by the slope.

\section{Statistical analysis}

Statistical analyses were carried out for the samples with OTA levels greater than the QL. Analysis of variance (ANOVA) was performed on the data after square root transformations to meet test assumptions. The Scott and $\mathrm{Knott}^{17}$ cluster analysis method for grouping means at $P<0.05$ was used. To test the contrast of interest (contamination of red wines versus white wines), the $F$ test at $P<0.05$ was applied. Analyses were performed using Statistics Package R-2.11.1 version (R Foundation for Statistical Computing, Vienna, Austria).

\section{RESULTS}

Validation of OTA measurements in wine and grape juice samples

The results of the validation of the extraction method for OTA in wine and grape juice samples are shown in Table 2. These results are within the standards recommended by the European Commission $^{18}$ for contamination values less than $1 \mu \mathrm{g} \mathrm{L}^{-1}$ and between 1 and $10 \mu \mathrm{g} \mathrm{L}^{-1}$ for wine and grape juice respectively.
The calibration curve obtained by linear regression was linear in the range from 0.6 to $111 \mu \mathrm{g} \mathrm{L}^{-1}$. The correlation coefficient was greater than 0.99 , as recommended by Green. ${ }^{19}$

\section{Levels of OTA in wine and grape juice samples}

The presence and mean values (minimum and maximum) of OTA found in the wine and grape juice samples are listed in Table 3. OTA was detected in 13 (38.24\%) samples analysed at concentrations ranging from 0.03 to $0.62 \mu \mathrm{g} \mathrm{L}^{-1}$. Of the positive samples, 12 were red and only one was white wine. Most of the red wine samples (75\%) had OTA contamination; however, OTA was not detected in any of the grape juice samples. The red wines in which OTA was not detected or in which the concentration was less than the QL $\left(0.03 \mu \mathrm{g} \mathrm{L}^{-1}\right)$ were obtained from Cabernet Sauvignon, Grenache, Cabernet Sauvignon RS: IAC-766 and Carmenère. These wines were prepared in the same period, which was different from the period of preparation of the positive samples, suggesting that climatic conditions of the harvest period may contribute to the presence of OTA contamination.

When we applied ANOVA to determine the source of variation in OTA levels in the positive samples, the type of grape proved to be significant in affecting OTA levels $(P<0.05$; Table 4$)$. We confirmed this finding using the Scott and $\operatorname{Knott}^{17}$ test $(P<0.05$; Fig. 1). As shown in Fig. 1, the mean OTA levels of the contaminated wines can be separated into statistically distinct groups (a, b, c, $\mathrm{d}$ and e). Some wines that were prepared from different grape varieties, such as Petit Verdot and Marselan Clone 980 RS: 1103-P, exhibited the same mean level of contamination. The greatest mean OTA value $\left(0.62 \mu \mathrm{g} \mathrm{L}^{-1}\right)$ was detected in a red wine sample prepared from the Syrah Clone 525 RS: IAC-313 variety (Fig. 2), and the level of contamination of this wine differed significantly from the rest (Fig. 1). The second most contaminated sample was also a red wine, obtained from the Syrah Clone 525 RS: 1103-P variety. On the other hand, the lowest OTA levels were detected in the Syrah, Tempranillo and Verdejo samples, which were statistically similar.

Unlike the type of grape, the winemaking period did not cause a statistical difference with regard to the OTA content (Table 4).

\begin{tabular}{|c|c|c|c|c|c|}
\hline Type of sample & OTA concentration $\left(\mu \mathrm{g} \mathrm{L}^{-1}\right)$ & Mean OTA detected $\left(\mu \mathrm{g} \mathrm{L}^{-1}\right)$ & Mean recovery ${ }^{\mathrm{a}}(\%)$ & No. of replicates & $\mathrm{CV}^{\mathrm{b}}(\%)$ \\
\hline \multirow[t]{2}{*}{ Wine } & 0.22 & $0.16 \pm 0.02$ & $70.91 \pm 7.95$ & 5 & 25.07 \\
\hline & 0.44 & $0.33 \pm 0.04$ & $74.09 \pm 10.33$ & 5 & 31.18 \\
\hline Grape juice & 2.78 & $2.65 \pm 0.05$ & $95.32 \pm 1.80$ & 2 & 2.67 \\
\hline
\end{tabular}

\begin{tabular}{|c|c|c|c|}
\hline Type of sample & Not detected or $<\mathrm{QL}^{\mathrm{a}}$ & Detected $^{\mathrm{b}}$ (>QL) & $\operatorname{Limits}^{\mathrm{c}}\left(\mu \mathrm{g} \mathrm{L}^{-1}\right)$ \\
\hline Red wine & $4 / 16(25 \%)$ & 12/16 (75\%) & $0.03-0.62$ \\
\hline White wine & 6/7 (85.7\%) & $1 / 7(14.3 \%)$ & 0.03 \\
\hline Grape juice & 11/11 (100\%) & $0 / 11$ & ND \\
\hline Total & 21/34 (61.76\%) & 13/34 (38.24\%) & $0.03-0.62$ \\
\hline
\end{tabular}


Table 4. ANOVA test for OTA content of contaminated wines

Source of variation Degrees of freedom Mean square $F$ calculated

$\begin{array}{lrrr}\text { Grape variety } & 10 & 52.867 & 68.20^{* *} \\ \text { Winemaking period } & 1 & 1.315 & 1.70^{\text {ns }} \\ \text { Variety } \times \text { period } & 1 & 2.171 & 2.80^{\text {ns }} \\ \text { Residue } & 13 & 0.775 & \end{array}$

$\mathrm{CV}=8.88 \%, R^{2}=98 \%$, mean $=123.86, \mathrm{SD}=0.593$

** Significant with $95 \%$ confidence; ${ }^{\text {ns }}$ not significant.

$\mathrm{CV}$, coefficient of variation; $R^{2}$, coefficient of determination; $\mathrm{SD}$, standard deviation.

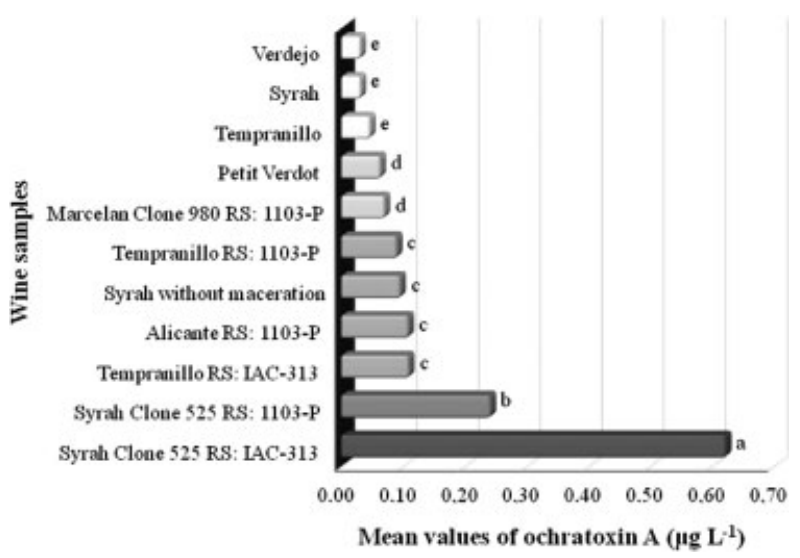

Figure 1. Mean OTA concentration detected in positive samples ( $>\mathrm{QL})$. Different letters indicate statistically significant differences by the Scott and $\mathrm{Knott}^{17}$ test at $P<0.05$.

The interaction between the grape variety and the winemaking period was also not statistically significant (Table 4).

The contrast between the red and white wines contaminated with OTA was statistically significant $(P<0.05)$, indicating that the mean level of contamination of the positive red wine samples differed significantly from the level detected in the white wines. Our results confirm previous studies that reported a greater occurrence and levels of OTA contamination in red wines compared with white wines. Taken together with Fig. 1, this result suggests that the Verdejo sample, although statistically similar to the Syrah and Tempranillo samples, had the lowest OTA value detected in this study, as it was the only white wine contaminated with OTA.
Interestingly, although we detected OTA contamination in some wine samples in this study, the levels detected were low, as they were less than the maximum tolerable limit for this toxin in wine and grape juice established by European ${ }^{12}$ and Brazilian ${ }^{13}$ legislation.

\section{DISCUSSION}

Our results indicate that red wines contain the highest levels of OTA contamination, which is in accordance with previous reports from Europe $^{9}$ and Brazil. ${ }^{20,21}$ The higher levels of OTA contamination in red wine compared with white wine is probably due to the characteristics of the winemaking process, especially because of the maceration of the grape marc. In addition, the duration of fermentation, which contributes significantly to the reduction of OTA content, ${ }^{22}$ is generally shorter for red wine than for white wine, allowing for increased removal of OTA from white wine compared with red wine.

In the process of making white wine, the solid parts of grapes are separated from the must after crushing, allowing minimal further contact between the must and the skin and seeds. However, during the process for making red and rosé wine, it is required that the solid parts ferment together with the must to allow for the extended time necessary for the extraction of colour and aromas. According to Lasram et al., ${ }^{22}$ this fermentation phase is when most of the OTA extraction from grapes into wine occurs, suggesting that grape skin is the main source of OTA.

Even though the highest level of OTA contamination observed among the samples tested was $0.62 \mu \mathrm{g} \mathrm{L}^{-1}$, this value is still less than the maximum limit $\left(2 \mu \mathrm{g} \mathrm{L}^{-1}\right)$ proposed by the European Commission ${ }^{12}$ and by Brazilian legislation. ${ }^{13}$ Previously, Shundo et al..$^{21}$ reported similar results where OTA levels in Brazilian red wines varied from 0.1 to $1.33 \mu \mathrm{g} \mathrm{L}^{-1}$. However, the authors suggested that, although the OTA content of Brazilian wines was low, small and continuous exposure to this mycotoxin could represent a risk to human health.

The low levels of OTA detected in the wine samples studied may be related to the semi-arid tropical climate of the region, where high temperatures are observed throughout the entire year (average of $27^{\circ} \mathrm{C}$ ). Lasram et al..$^{23}$ suggested that, since A. carbonarius produces more OTA at lower temperatures $\left(15-20^{\circ} \mathrm{C}\right)$, European climate conditions are more permissive to OTA contamination of grapes than those in regions with a tropical climate, such as Brazil.

We did not detect significant levels of OTA in the grape juice samples tested. Similarly, in a previous study performed in Brazil, none of the 38 samples of grape juice tested was contaminated

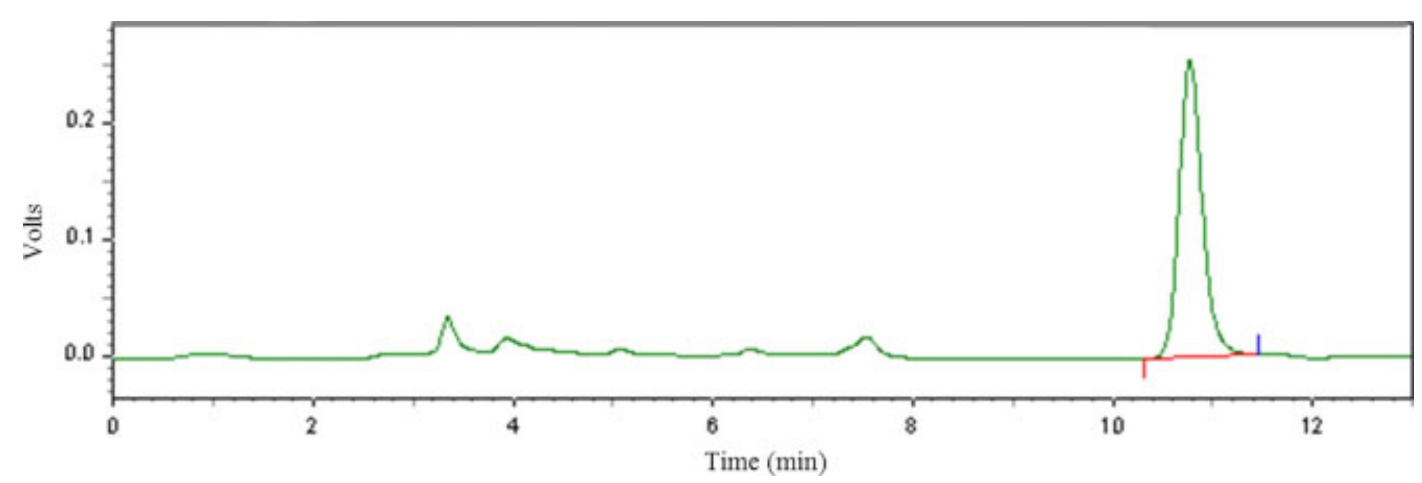

Figure 2. Chromatogram of wine sample prepared from Syrah Clone 525 RS: IAC-313 variety. 
with OTA. ${ }^{21}$ This may be due to the type of grapes used, the geographic origin of the grapes, the climatic conditions and/or the different practices for growing the grapes, which affect the growth of ochratoxigenic fungi and production of OTA. In contrast to what has been observed in Brazilian grape juices, Dachoupakan et al. ${ }^{24}$ found OTA in grape juice samples originating from France.

The Scientific Committee on Food 25 has established an

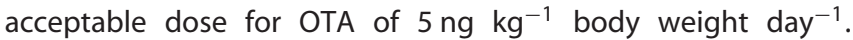
Considering that the average wine consumption in Brazil is $5 \mathrm{~mL}$ day $^{-1}$, that the highest level of OTA found in our study was $0.62 \mu \mathrm{g}$ $\mathrm{L}^{-1}$ and that the average body weight of a Brazilian is $70 \mathrm{~kg}$, we can estimate that the maximum daily consumption of OTA in Brazil is $0.88 \%$ of the daily tolerable dose. Similarly, considering the mean OTA content of red $\left(0.098 \mu \mathrm{g} \mathrm{L}^{-1}\right)$ and white $\left(0.004 \mu \mathrm{g} \mathrm{L}^{-1}\right)$ wine samples in our study, the average daily consumption is estimated to be only 0.14 and $0.005 \%$ of the daily tolerable dose respectively.

Further studies investigating OTA contamination in Brazilian wine and grape juice are necessary to gain a better understanding of the factors that significantly contribute to the presence and levels of the toxin in these products. Understanding the critical factors of OTA contamination will allow for the development of better production methods to minimise the risk of exposure to OTA and will facilitate the maintenance of low levels of contamination in grape derivatives.

\section{ACKNOWLEDGEMENTS}

The authors of this study would like to thank CNPq for financial support (project CNPq/MAPA/SDA N ${ }^{\circ}$ 064/2008) and FAPEMIG for granting a scholarship to Michelle F Terra.

\section{REFERENCES}

1 Anli E and Alkis IM, Ochratoxin A and brewing technology: a review. J Inst Brew 116:23-32 (2010).

2 Solfrizzo M, Avantaggiato G, Panzarini G and Visconti A, Removal of ochratoxin A from contaminated red wines by repassage over grape pomaces. J Agric Food Chem 58:317-323 (2010).

3 IARC, Some Naturally Occurring Substances:Food Items and Constituents, Heterocyclic Aromatic Amines and Mycotoxins, Vol. 56 of Monographs on the Evaluation of Carcinogenic Risks to Humans. International Agency for Research on Cancer, Lyon (1993).

4 Zimmerli B and Dick R, Determination of ochratoxin A at the ppt level in human blood, serum, milk and some foodstuffs by highperformance liquid chromatography with enhanced fluorescence detection and immunoaffinity column clean-up: methodology and Swiss data. J Chromatogr A 666:85-99 (1995).

5 Hocking AD, Leong SL, Kazi BA, Emmett RW and Scott ES, Fungi and mycotoxins in vineyards and grape products. Int J Food Microbiol 119:84-88 (2007).

6 Visconti A, Perrone G, Cozzi G and Solfrizzo M, Managing ochratoxin A risk in the grape-wine food chain. Food Addit Contam 25:193-202 (2008).
7 Palumbo JD, O'Keeffe TL, Vasquez SJ and Mahoney NE, Isolation and identification of ochratoxin A-producing Aspergillus section Nigri strains from California raisins. Lett App/Microbio/ 52:330-336(2011).

8 Chulze SN, Magnoli CE and Dalcero AM, Occurrence of ochratoxin A in wine and ochratoxigenic mycoflora in grapes and dried vine fruits in South America. Int J Food Microbiol 111:5-9 (2006).

9 Bejaoui H, Mathieu F, Taillandier P and Lebrihi A, Black aspergilli and ochratoxin A production in French vineyards. Int J Food Microbiol 111:46-52 (2006).

10 Duarte SC, Pena A and Lino CM, Ochratoxin A non-conventional exposure sources: a review. Microchem J 93:115-120 (2009).

11 Varga J and Kozakiewicz Z, Ochratoxin in grapes and grape-derived products. Trends Food Sci Technol 17:72-81 (2006).

12 European Commission, European Commission Regulation No. $123 / 2005$. Amending Regulation (EC) No. 466/2001 as regards ochratoxin A. Off J Eur Union 25:3-5 (2005).

13 Ministério da Saúde, Agência Nacional de Vigilância Sanitária (ANVISA), Regulamento Técnico sobre os limites máximos tolerados (LMT) para micotoxinas em alimentos (Resolução RDC No. 7, fevereiro de 2011). Diário Oficial da União, Poder Executivo, No. 37 (2011).

14 Peynaud Eand Blouin J, Connaissanceet Travaildu Vin.LaVigne/Dunod, Paris (1997).

15 British Standards Institute (BSI), Foodstuffs. Determination of Ochratoxin $A$ in Wine and Beer. HPLC Method with Immunoaffinity Column Cleanup. BS EN 14133 (2003)

16 AOAC, Official Methods of Analysis (16th edn). Association of Official Analytical Chemists, Washington, DC (1997).

17 Scott AJ and Knott MA, A cluster analysis method for grouping means in the analysis of variance. Biometrics 30:507-512 (1974).

18 European Commission, European Commission Regulation No. $401 / 2006$. Laying down the methods of sampling and analysis for the official control of the levels of mycotoxins in foodstuffs. Off J Eur Union 70:12-34 (2006).

19 Green JM, A practical guide to analytical method validation. AnalChem News Features 68:305-309 (1996)

20 Rosa CA, Magnoli CE, Fraga ME, Dalcero AM and Santana DM, Occurrence of ochratoxin $A$ in wine and grape juice marketed in Rio de Janeiro, Brazil. Food Addit Contam 21:358- 364 (2004).

21 Shundo L, de Almeida AP, Alaburda J, Ruvieri V, Navas SA, Lamardo LCA, et al, Ochratoxin $A$ in wines and grape juices commercialized in the city of São Paulo, Brazil. Braz J Microbiol 37:533-537 (2006)

22 Lasram S, Mani A, Zaied C, Chebil S, Abid S, Bacha H, et al, Evolution of ochratoxin A content during red and rose vinification. J Sci Food Agric 88:1696-1703 (2008).

23 Lasram S, Oueslati S, Valero A, Marin S, Ghorbel A and Sanchis V, Water activity and temperature effects on fungal growth and ochratoxin $A$ production by ochratoxigenic Aspergillus carbonarius isolated from Tunisian grapes. J Food Sci 75:89-97 (2010).

24 Dachoupakan C, Ratomahenina R, Martinez V, Guiraud JP, Baccou JC and Schorr-Galindo S, Study of the phenotypic and genotypic biodiversity of potentially ochratoxigenic black Aspergillus isolated from grapes. Int J Food Microbiol 132:14-23 (2009).

25 Scientific Committee on Food, Opinion of the Scientific Committee on Food on Ochratoxin A [Online]. (1998). Available: http://ec. europa.eu/food/fs/sc/scf/out14_en.html [15 November 2010]. 